\title{
LncRNA NEAT1 Promotes Deterioration of Hepatocellular Carcinoma Based on In Vitro Experiments, Data Mining, and RT-qPCR Analysis
}

\author{
Zhi-an Ling ${ }^{\mathrm{a}} \quad$ Dan-dan Xiong ${ }^{\mathrm{b}} \quad$ Rong-mei Meng $^{\mathrm{b}} \quad$ Jie-Mei Cen ${ }^{\mathrm{b}} \quad \mathrm{Na}$ Zhao $^{\mathrm{b}}$ \\ Gang Chen ${ }^{b}$ Ruo-lin Lic Yi-wu Dang ${ }^{b}$ \\ aDepartment of Emergency, Second Affiliated Hospital of Guangxi Medical University, Nanning, \\ Guangxi Zhuang Autonomous Region, 'bepartment of Pathology, First Affiliated Hospital of Guangxi \\ Medical University, Nanning, Guangxi Zhuang Autonomous Region, 'Department of Scientific Research, \\ First Affiliated Hospital of Guangxi Medical University, Nanning, Guangxi Zhuang Autonomous Region \\ China
}

\section{Key Words}

Hepatocellular carcinoma $\bullet$ NEAT1 $•$ Biological functions $•$ Clinical value $\bullet$ Molecular mechanism

\begin{abstract}
Background/Aims: Accumulated evidence indicates that IncRNA NEAT1 has important roles in various malignant tumors. In this study, we conducted a comprehensive analysis to explore the exact role of NEAT1 in hepatocellular carcinoma (HCC). Methods: The effects of NEAT1 on cell proliferation, apoptosis, migration, and invasion were measured by in vitro experiments. The expression level and clinical value of NEAT1 in HCC was evaluated based on data from The Cancer Genome Atlas (TCGA), Oncomine, and in-house real-time quantitative (RT-qPCR). Gene Ontology (GO), Kyoto Encyclopedia of Genes and Genomes (KEGG) pathway, and protein-protein interaction (PPI) network analyses were conducted to investigate the potential molecular mechanisms of NEAT1. Results: NEAT1 siRNA not only inhibited proliferation, migration, and invasion of HCC cells but also induced HCC cell apoptosis. A total of four records from TCGA, Oncomine, and RT-qPCR analysis were combined to assess the expression level of NEAT1 in HCC. The pooled standard mean deviation (SMD) indicated that NEAT1 was upregulated in $\mathrm{HCC}(\mathrm{SMD}=0.54 ; 95 \% \mathrm{CI}, 0.36-0.73 ; P<0.0001)$. The area under the curve value of the summary receiver operating characteristic curve was 0.71 . NEAT1 expression was also related to race $(P=0.025)$ and distant metastasis $(P=0.002)$. Additionally, the results of $\mathrm{GO}$, KEGG pathway, and PPI network analyses suggest that NEAT1 may promote the progression of HCC by interacting with several tumor-related genes (SP1, MDM4, CREBBP, TRAF5, CASP8, TRAF1, KAT2A, and HIST4H4). Conclusions: NEAT1 contributes to the deterioration of HCC and provides a potential biomarker for the diagnosis and therapy of HCC.

Zhi-an Ling and Dan-dan Xiong contributed equally to this work.

Ruo-lin Li

and Yi-wu Dang

Department of Scientific Research and Pathology, First Affiliated Hospital of Guangxi Medical University, Nanning, Guangxi Zhuang Autonomous Region 530021, (China) E-Mail ruolin8297@163.com; dangyiwu@126.com
\end{abstract}

\section{KARGER}




\section{Cellular Physiology Cell Physiol Biochem 2018;48:540-555 \begin{tabular}{ll|l} 
DOI: 10.1159/000491811 & $\begin{array}{l}\text { () 2018 The Author(s). Published by S. Karger AG, Basel } \\
\text { www.karger.com/cpb }\end{array}$
\end{tabular}}

Ling et al.: NEAT1 Promotes Deterioration of Hepatocellular Carcinoma

\section{Introduction}

Primary liver cancer is the sixth most common malignancy worldwide and the second leading cause of cancer mortality, accounting for an estimated 40, 710 diagnoses and 28, 920 deaths in 2017 [1]. In most countries, hepatocellular carcinoma (HCC) represents the majority of liver cancers. Although treatments for HCC have improved and diversified from traditional surgery to more effective therapies, such as liver transplantation, chemotherapy, radiotherapy, and thermotherapy, the survival rates for HCC are unfortunately poor owing to the high invasive ability of HCC cells [2]. Therefore, it is urgent to explore the genetic mechanisms of HCC and to search for personalized treatment options.

Long non-coding RNAs (lncRNAs), which contain more than 200 nucleotides [3], have gradually become a large research focus in recent years. It has been shown that lncRNAs play essential roles in maintaining cellular homeostasis during cell development and are vital elements in the pathophysiology of cancer [3-8]. A growing number of studies have shown that many lncRNAs are associated with HCC. For example, Panzitt et al. [9] found that the upregulation of IncRNA HULC could downregulate tumor suppressor gene P18 and thus promote HCC cell growth. Sui et al. [10] reported that lncRNA linc-USP16 may negatively regulate migration and invasion of HCC cells by regulating PTEN expression. Wang et al. [11] demonstrated that IncRNA UCA1 inhibited the malignant behavior of HCC cells through downregulation of miR-216 and activation of the FGFR1/ERK pathway. However, there are still numerous novel IncRNAs that remain uncharacterized.

Nuclear paraspeckle assembly transcript 1 (NEAT1), a structural component of paraspeckles, consists of two variants: 3.7-kb NEAT1_v1 (MENE) and 23-kb NEAT1_v2 (MEN $\beta)$ $[12,13]$. Some investigators have demonstrated that NEAT1 plays essential roles in several malignancies, including breast cancer, lung cancer, laryngeal squamous cell cancer, gastric cancer, nasopharyngeal carcinoma, pancreatic carcinoma, and colorectal cancer [14-20]. Our research group previously conducted a comprehensive analysis of the clinical value of NEAT1 in digestive system malignancies based on 57 microarray and RNA-seq datasets, ultimately finding that NEAT1 may play different roles in the initiation and progression of digestive system cancers [21]. The biological functions of NEAT1 in HCC have also been investigated in previous studies. A study conducted by Mang et al. [22] showed that NEAT1 stimulated the proliferation and invasion of HCC cells in vitro. Wang et al. [23] also found that NEAT1 could boost cell invasion and proliferation in HCC through inhibition of miR-613 expression.

In this study, we not only studied the biological effects of NEAT1 on HCC cells in vitro but also systematically analyzed the expression level and clinical significance of NEAT1 in HCC based on RNA-seq and microarray datasets from The Cancer Genome Atlas (TCGA) and Oncomine databases. Additionally, real-time quantitative PCR (RT-qPCR) was conducted to verify the expression of NEAT1. Furthermore, we analyzed the genes coexpressed with NEAT1 according to Gene Ontology (GO) functional annotation and Kyoto Encyclopedia of Genes and Genomes (KEGG) pathway analyses. A protein-protein interaction (PPI) network was also constructed. The overall design of the present study is shown in Fig. 1.

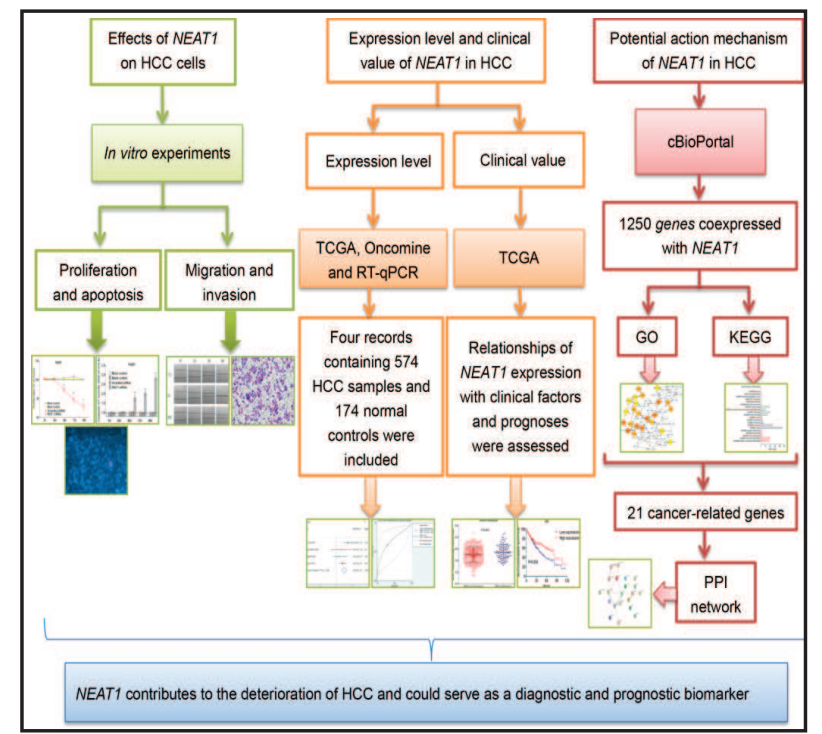

Fig. 1. Flow chart of the overall design of the present study. 


\section{Cellular Physiology Cell Physiol Biochem 2018;48:540-555 \begin{tabular}{l|l} 
and Biochemistry Publisned onlnne: July 18, 2018 & $\begin{array}{l}\text { ( ) 2018 The Author(s). Published by S. Karger AG, Basel } \\
\text { www.karger.com/cpb }\end{array}$
\end{tabular}}

Ling et al.: NEAT1 Promotes Deterioration of Hepatocellular Carcinoma

\section{Materials and Methods}

\section{Patients and samples}

A total of 101 tumor tissues and adjacent non-tumorous specimens were collected from patients who were diagnosed with HCC pathologically at the First Affiliated Hospital of Guangxi Medical University (Nanning, Guangxi, People's Republic of China) from March 2010 to December 2011. All cases had not received any adjuvant chemotherapy or radiotherapy before surgery. Adjacent non-tumorous tissues were resected at least $2 \mathrm{~cm}$ away from the tumorous node. The Ethical Committee of the First Affiliated Hospital of Guangxi Medical University approved his study.

\section{Cell culture and transfection}

Two human HCC cell lines, HepG2 and HepB3, were obtained from the American Type Culture Collection (Manassas, VA) and cultured as described previously [24]. After being seeded into a 96-well plate $\left(2.5 \times 10^{3}\right.$ cells per well) and incubated at $37^{\circ} \mathrm{C}$ for $24 \mathrm{~h}$, HCC cells were transfected with a blank control, mock control, scrambled siRNA (5'-GCTTGAATTAACTGCAGGCGTATAT-3'), or NEAT1 siRNA (5'-GUGAGAAGUUGCUUAGAAACUUUCC-3') at a concentration of $200 \mathrm{nmol} / \mathrm{L}$ for up to $96 \mathrm{~h}$ with CombiMag Magnetofection (OZ Bioscences, Marseille, France). Then, we collected samples at 0, 24, 48, 72, and $96 \mathrm{~h}$ for further analysis. RT-qPCR was utilized to detect NEAT1 knockdown efficiency.

\section{RT-qPCR}

Cellular or tissue RNA isolation was conducted on an ABI PRISM 6100 PrepStation (Thermo Fisher Scientific, Waltham, MA). RT-qPCR was performed with an Applied Biosystems PCR 7900 (Thermo Fisher Scientific) following the manufacturer's instructions. For tissue RT-qPCR, the primer sequences were 5'-TGGCTAGCTCAGGGCTTCAG-3' (cis) and 5'-TCTCCTTGCCAAGCTTCCTTC-3' (trans). For cellular RT-qPCR, the primer sequences were $5^{\prime}$-CTTCCTCCCTTTAACTTATCCATTCAC-3' (cis), $5^{\prime}$-CTCTTCCTCCACCATTACCAACAATAC-3' (trans). The NEAT1 abundance in each sample was normalized to its reference. The expression of NEAT1 in tissues was calculated using the formula $2^{-\triangle \mathrm{Cq}}$, and the change ratio of NEAT1 in cells was determined using the formula $2^{-\Delta \Delta \mathrm{Cq}} \times 100 \%$.

\section{Biological function of NEAT1 in HCC by in vitro experiments}

Cell proliferation and viability were determined by colorimetric tetrazolium (MTS) assay (CellTiter96 AQueous One Solution Cell Proliferation Assay G3580, Promega, Madison, WI) and fluorometric detection of resorufin (CellTiter-Blue Cell Viability Assay, G8080, Promega), respectively.

Cell apoptosis was detected using Hoechst 33342 (Sigma-Aldrich, St. Louis, MO) and propidium iodide (PI; Sigma-Aldrich) double-fluorescent chromatin staining. Two reviewers independently counted the viable and apoptotic cells in 10 fields of each well under a 200× magnification microscope after Hoechst 33342/PI staining for $96 \mathrm{~h}$.

Caspase-3/7 activity was detected with a synthetic rhodamine-labeled caspase-3/7 substrate (ApoONEW Homogeneous Caspase-3/7 Assay, G7790, Promega). Cell migration was monitored using a woundhealing assay. Photographs of the wounds were obtained at $0,12,24$, and $48 \mathrm{~h}$ and analyzed with Adobe Photoshop CS6 software (Adobe, San Jose, CA) to observe cell migration and calculate wound width. The wound widths at 12,24 , and $48 \mathrm{~h}$ were compared with the wound width of the blank control at $0 \mathrm{~h}$. A 24-well Transwell assay (Corning Costar, Corning, NY) was conducted to detect cell invasion. Cells were counted in five random fields under a microscope. All experiments were performed following the procedures illustrated in previous studies [24-27].

\section{Statistical analysis}

Statistical analysis was conducted using SPSS 22.0 (IBM, Armonk, New York). The results represent three independent experiments. Values are shown as the mean \pm standard deviation (SD). Significance between groups was analyzed via a one-way analysis of variance (ANOVA). For statistically significant ANOVA results, the least significant difference method for multiple comparisons was applied. Statistical significance was determined at the $P<0.05$ level. 


\section{Cellular Physiology Cell Physiol Biochem 2018;48:540-555 \begin{tabular}{l|l|l|l} 
DOI: 10.1159/000491811 & (O) 2018 The Author(s). Published by S. Karger AG, Basel
\end{tabular}

Data mining from TCGA and Oncomine

Based on the following criteria, IncRNA sequencing and microarray datasets available up to August 28, 2017 were downloaded from TCGA [28] and Oncomine [29]: (1) both HCC and normal control tissues were included in the study, and each group included more than two samples; (2) the expression data of NEAT1 was provided directly or could be calculated; and (3) the species was human.

Two researchers (Z.-A.L. and D.-D.X.) collected the basic information from each dataset: the first author, publication year, region, data source, sample size, and NEAT1 expression (mean \pm SD) in HCC and normal control groups. All disagreements were resolved by discussion with a third (G.C.) and fourth (R.-L.L.) investigator.

The overall standard mean deviation (SMD) and 95\% confidence intervals (CIs) were calculated to assess the pooled expression level of NEAT1 in HCC. A summary receiver operating characteristic (SROC) curve was generated, and the area under the curve (AUC) value was calculated to further investigate the ability of NEAT1 in discriminating HCC patients from normal controls. Begg's and Egger's tests were applied to estimate publication bias [30]. All analyses were carried out using STATA 12.0 (Stata Corporation, College Station, TX). The $P<0.05$ threshold was used to determine statistical significance.

The relationships between NEAT1 expression and the clinicopathological factors and prognoses were estimated with data from the TCGA. An independent sample $t$-test was employed to assess the relationships between NEAT1 expression and the clinicopathological parameters. All HCC patients were divided into lowexpression and high-expression groups according to the median expression value of NEAT1. Then, a KaplanMeier survival curve with a log-rank test was applied to evaluate the prognostic value of NEAT1 in HCC. Univariate and multivariate Cox regression analyses were further conducted to determine whether NEAT1 was an independent prognostic biomarker.

\section{Bioinformatics analysis of NEAT1 co-expressed genes}

The genes co-expressed with NEAT1 were collected from the cBioPortal website [31]. GO functional annotation and KEGG pathway analyses were performed with the DAVID online tool [32]. We selected coexpressed genes that participated in cancer-related pathways to construct a PPI network using the STRING online database [33]. Then, we selected genes that interacted in the PPI network for further analysis. Independent sample $t$-tests were applied to evaluate the expression levels of these selected genes using expression data from TCGA. A Pearson correlation analysis was employed to assess the associations between the selected genes and NEAT1.

\section{Results}

Biological effects of NEAT1 on HCC cells in vitro

NEAT1 siRNA inhibited proliferation of HCC cells

In this study, NEAT1 siRNA effectively decreased NEAT1 expression in HepG2 and HepB3 cells, with knockdown efficiencies ranging from 75\% to 80\%. An MTSassay was used, showing a time-independent inhibitory effect of NEAT1 siRNA on the proliferation of HepG2 and HepB3 cells (Fig. 2A, B). Consistent with the MTS assay result, the fluorometric resorufin viability assay revealed that the viability of cells transfected with NEAT1 siRNA was markedly decreased compared with those cells transfected with the mock control.

\section{NEAT1 siRNA induced apoptosis of HCC cells}

Whether NEAT1 siRNA influenced apoptosis of HCC cells remained to be clarified. Thus, fluorescent caspase-3/7 assays and Hoechst 33342/PI double-fluorescent chromatin staining analyses were conducted. Caspase- $3 / 7$ activity and apoptosis were remarkably increased in HCC cells with NEAT1 siRNA transfection (Fig. 3A, B, C, D). In addition, viable and apoptotic cells were counted under a microscope (200× magnification) following the Hoechst 33342/PI staining for $96 \mathrm{~h}$. The result showed that NEAT1 siRNA significantly boosted HCC cell apoptosis and decreased cell viability (Fig. 3E). 


\section{Cellular Physiology Cell Physiol Biochem 2018;48:540-555 \begin{tabular}{l|l} 
and Biochemistry Publisned onIme: July 18, 2018 & $\begin{array}{l}\text { ( ) } 2018 \text { The Author(s). Published by S. Karger AG, Basel } \\
\text { www.karger.com/cpb }\end{array}$
\end{tabular}}

Ling et al.: NEAT1 Promotes Deterioration of Hepatocellular Carcinoma

NEAT1 siRNA suppressed migration and invasion of HCC cells

The effect of NEAT1 on cell migration and invasion was examined in HepB3 cells using wound-healing and Transwell assays. NEAT1 siRNA caused significant reductions in the wound-healing rate and invasiveness of the HepB3 cells compared with the blank control (Fig. 4).

Expression level and clinical significance of NEAT1 in HCC

Expression level of NEAT1 in HCC

A total of four records containing 574 HCC samples and 174 non-cancerous specimens were included in our study, and the key information on the four records is presented in Table 1.

The expression level of NEAT1 in each included dataset was visualized using scatter plots and receiver operating characteristic curves (Fig. 5). Owing to the low reliability of individual studies, we combined the four records to obtain a stronger result. The pooled result from a fixed-effects model $\left(I^{2}=37.7 \% ; P=0.186\right)$ indicated that NEAT1 was upregulated in HCC (SMD, 0.54; 95\% CI, 0.36-0.73; $P<$

Fig. 3. NEAT1 siRNA induced apoptosis of HepG2 and HepB3 cells. (A) Effect of NEAT1 on HepG2 cell apoptosis per caspase 3/7 activity as evaluated by the Apo-ONE® Homogeneous Caspase-3/7 Assay. (B) Effect of NEAT1 on HepB3 cell apoptosis per caspase $3 / 7$ activity as evaluated by the ApoONE® Homogeneous Caspase-3/7 Assay. (C) Effect of NEAT1 on HepG2 cell apoptosis as evaluated by fluorescence microscopy after Hoechst 33342 and propidium iodide (PI) double-fluorescent chromatin staining. (D) Effect of NEAT1 on HepB3 cell apoptosis as evaluated by fluorescence microscopy after Hoechst 33342/PI staining. (E) NEAT1 siRNA inhibited viability and promoted apoptosis of HepG2 and HepB3 cells. The following cell types were identified: viable cells (Hoechst 33342-positive/PInegative), early apoptotic cells (Hoechst 33342-positive/PI-negative with blue fragmentation in the cells), late apoptotic cells (Hoechst 33342-positive/PI-positive, with red fragmentation in the cells), and necrotic cells (PI-positive with debris signals). ${ }^{*} \mathrm{P}<0.05$; ${ }^{* *} \mathrm{P}<0.01$; ${ }^{* * *} \mathrm{P}<0.001$.

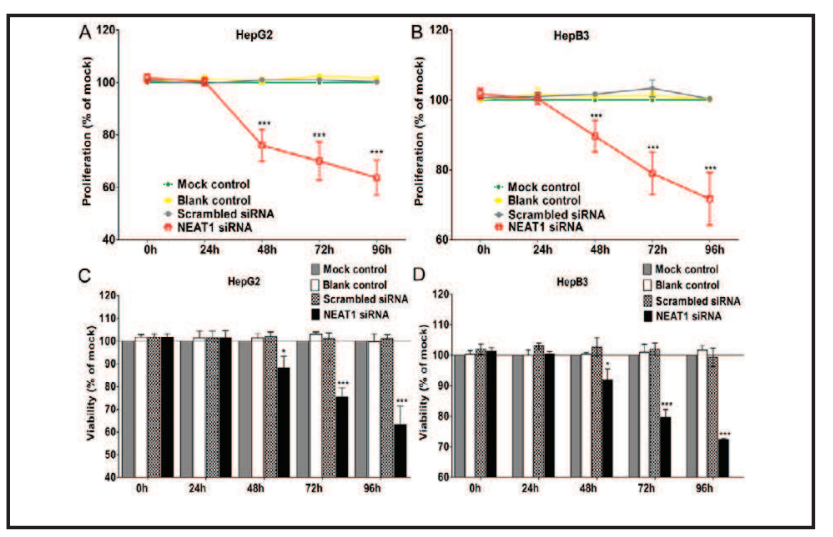

Fig. 2. NEAT1 siRNA inhibited the proliferation and viability of HepG2 and HepB3 cells. (A) Effect of NEAT1 on HepG2 cell proliferation according to the colometric tetrazolium (MTS) assay. (B) Effect of NEAT1 on HepB3 cell proliferation according to the MTS assay. (C) Effect of NEAT1 on HepG2 cell viability according to the CellTiter-Blue Cell Viability Assay. (D) Effect of NEAT1 on HepB3 cell viability according to the CellTiter-Blue Cell Viability Assay. ${ }^{*} \mathrm{P}<0.05$; ${ }^{* * *} \mathrm{P}<0.001$.

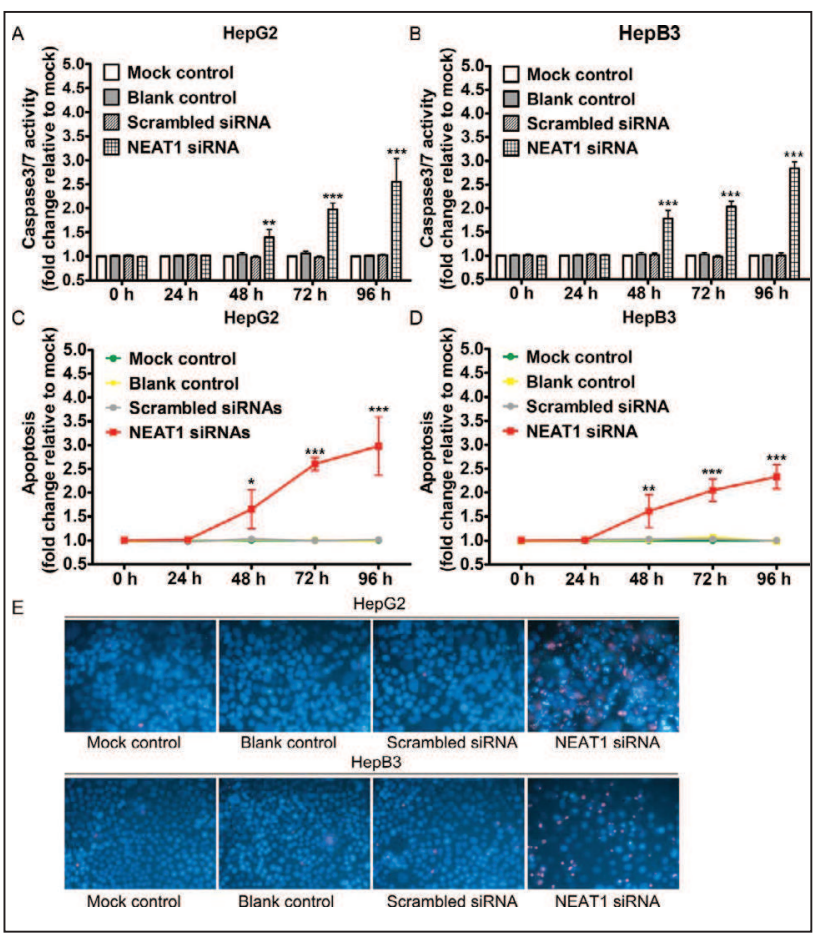




\section{Cellular Physiology Cell Physiol Biochem 2018;48:540-555

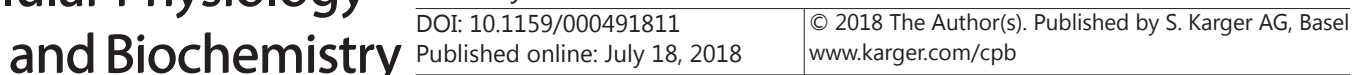

Ling et al.: NEAT1 Promotes Deterioration of Hepatocellular Carcinoma

Table 1. Key information on the four included data sources. HCC, hepatocellular carcinoma; SD, standard deviation; TCGA, The Cancer Genome Atlas; RT-qPCR, real-time quantitative PCR

\begin{tabular}{lcccccc}
\hline & & & \multicolumn{2}{c}{ Sample size } & \multicolumn{2}{c}{ Mean \pm SD } \\
First author (publication year) & Region & Data source & HCC & Normal & HCC & Normal \\
\hline TCGA (2017) & USA & TCGA & 374 & 50 & $13.32 \pm 1.20$ & $12.36 \pm 1.24$ \\
Wurmbach E (2007) & USA & Oncomine & 35 & 10 & $12.38 \pm 0.77$ & $12.12 \pm 0.82$ \\
Mas VR (2007) & USA & Oncomine & 64 & 19 & $5.81 \pm 0.83$ & $5.59 \pm 0.97$ \\
In-house RT-qPCR (none) & China & RT-qPCR & 101 & 101 & $5.89 \pm 2.55$ & $4.90 \pm 1.89$ \\
\hline
\end{tabular}

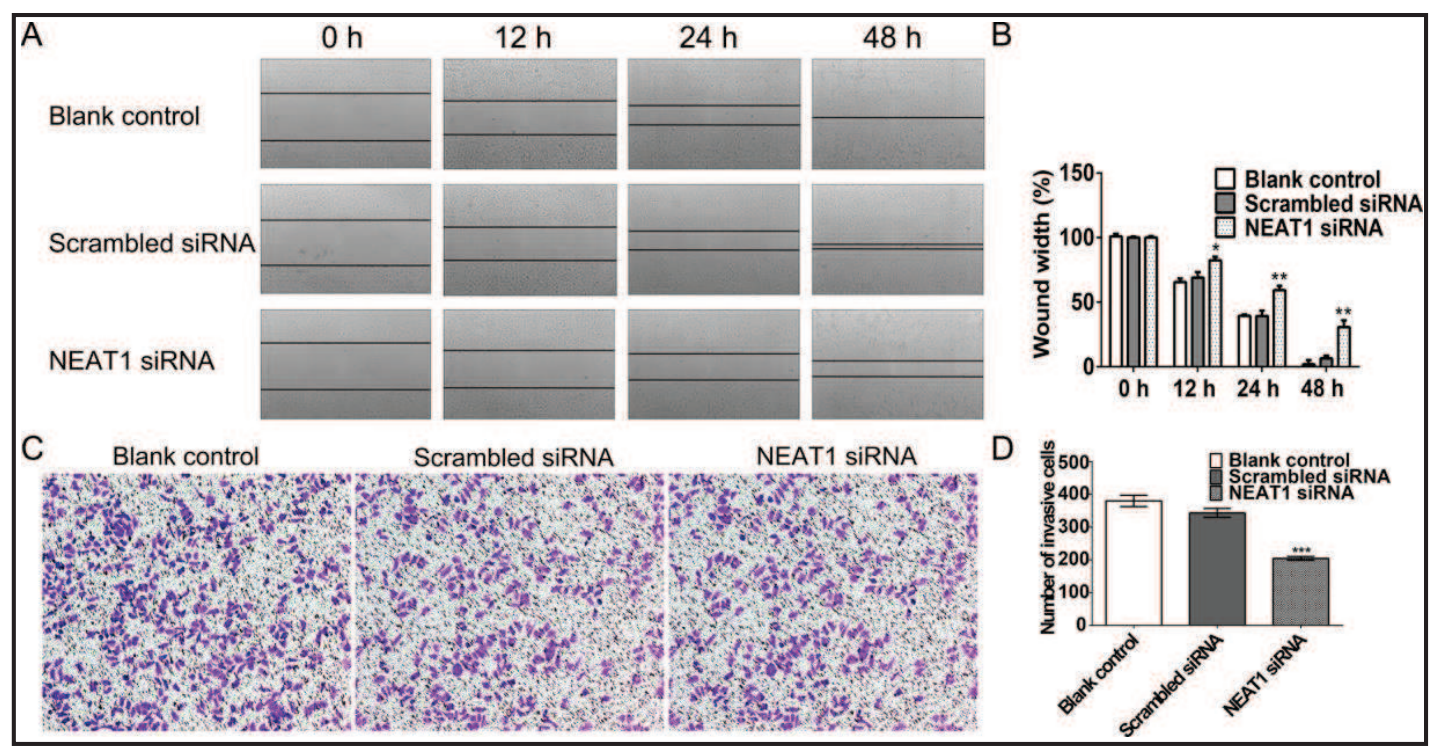

Fig. 4. NEAT1 siRNA reduced migration and invasion of HepB3 cells. (A) Cell migration was examined in wound-healing assays. (B) Wound width was calculated. (C) Cell invasion was examined with Transwell assays. (D) The number of invasive cells was counted. ${ }^{*} \mathrm{P}<0.05$; ${ }^{* *} \mathrm{P}<0.01$; ${ }^{* * *} \mathrm{P}<0.001$

0.0001; Fig. 6A). No publication bias was found (Begg's $P=0.34$; Egger's $P=0.482$; Fig. 6B).

To further determine the ability of NEAT1 expression to discriminate HCC from normal controls, we generated an SROC curve. The overall AUC value of NEAT1 in HCC was 0.70 (95\% CI, 0.65-0.73; Fig. 6C), with a sensitivity and specificity of 0.61 (95\% CI, 0.42-0.77) and 0.71 (95\% CI, 0.42-0.89), respectively.

\section{Clinical significances of NEAT1 in HCC}

NEAT1 expression data and corresponding clinical and survival information were obtained from TCGA. Our results revealed that NEAT1 was significantly related to race $(P$ $=0.025$; Fig. 7A $)$ and distant metastasis $(P=0.002$; Fig. 7B) but not related to gender, age, clinical TNM stage, histological grade, lymph node metastasis, or vascular invasion (Table 2). A Kaplan-Meier survival curve was generated to gain insight into the prognostic role of NEAT1 in HCC. The results revealed that high NEAT1 expression indicated higher overall survival (OS; $P=0.036$; Fig. 7C), while no significant correlation was found between NEAT1 expression and disease-free survival $(P=0.257$; Fig. 7D). Then, we further performed univariate and multivariate Cox regression analyses to evaluate the effect of NEAT1 expression on OS (Table 3 ). The hazard ratio (HR) from the univariate Cox regression analysis indicated that NEAT1 expression was significantly related to OS ( $\mathrm{HR}, 0.57 ; 95 \% \mathrm{CI}, 0.344-0.944 ; P=0.029$ ). More importantly, the multivariate Cox regression analysis showed that NEAT1 was still associated with OS (HR, 0.568; 95\% CI, 0.329-0.98; $P=0.042$ ) after adjusting for age, race, gender, histological grade, stage, lymph node metastasis, distant metastasis, and vascular invasion, which suggests that NEAT1 is an independent prognostic biomarker for patients with HCC. 


\section{Cellular Physiology Cell Physiol Biochem 2018;48:540-555 \begin{tabular}{ll|l} 
DOI: 10.1159/000491811 & 2018 The Author(s). Published by S. Karger AG, Basel \\
\hline
\end{tabular} and Biochemistry Publisned onlne: July 18, 2018 www.karger.com/cpb}
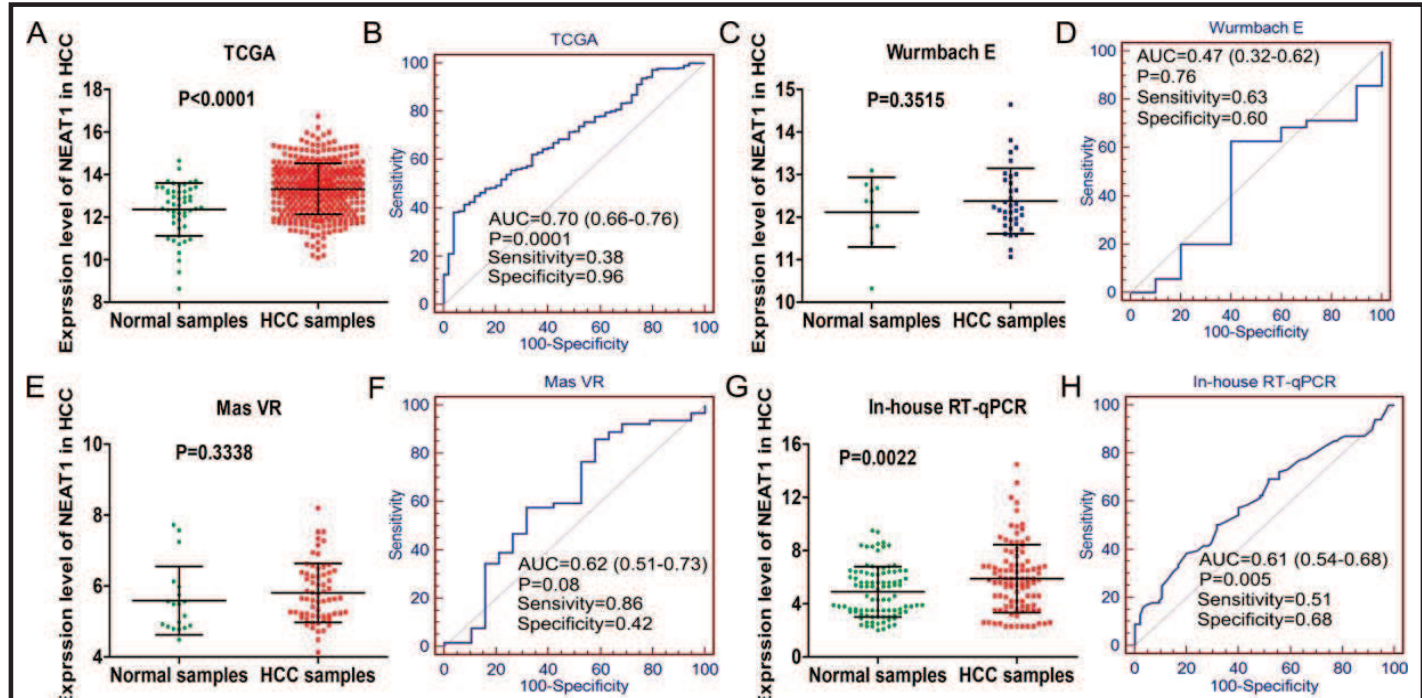

Fig. 5. Expression level of NEAT1 in hepatocellular carcinoma (HCC) based on data from (A and B) The Cancer Genome Atlas (TCGA), (C and D) Wurmbach E, (E and F) Mas VR, and (G and H) our in-house RTqPCR analyses.

Fig. 6. Meta-analysis for NEAT1 expression in hepatocellular carcinoma (HCC). (A) Forest plot of the four records evaluating NEAT1 expression in HCC (fixed-effects model). Standard mean deviation (SMD) $>0$ indicates that NEAT1 is upregulated in HCC tissues compared with the noncancerous tissues. (B) Funnel plot assessing publication bias in the four datasets. (C) Summary receiver operating characteristic (SROC) curve for distinguishing HCC patients from the normal controls using NEAT1 expression.

\section{Potential molecular mechanism of NEAT1 in HCC}

$G O$ and KEGG pathway analyses of co-expressed genes of NEAT1

A total of 1, 250 genes coexpressed with NEAT1 were selected for GO and KEGG pathway analyses. The GO terms for biological process, cellular component, and molecular function networks were constructed with the BINGO plugin for Cytoscape 3.3.0 software (Fig. 8). The top five GO

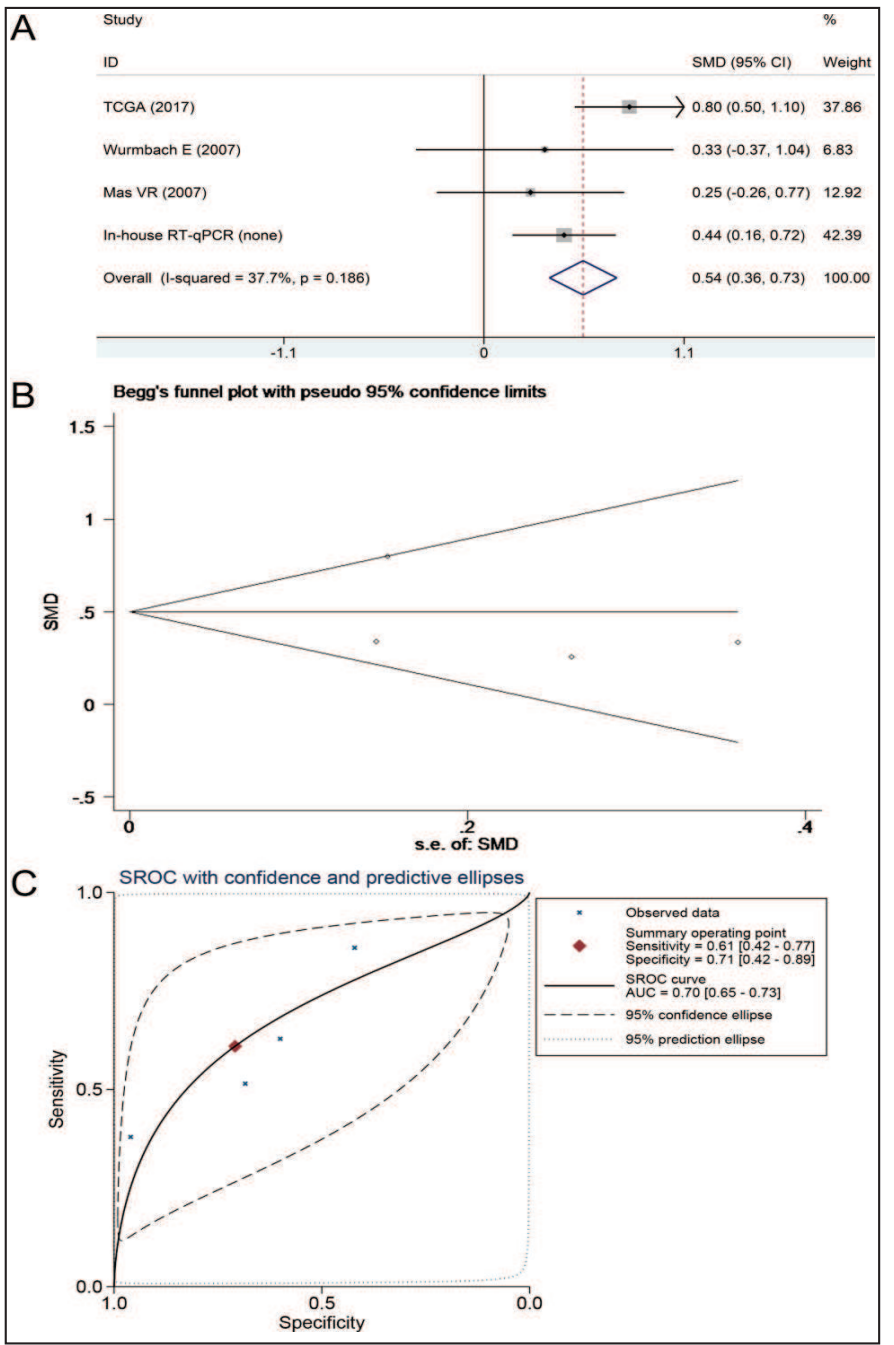




\section{Cellular Physiology Cell Physiol Biochem 2018;48:540-555 \begin{tabular}{c|l} 
and B 10.1159/000491811 2018 The Author(s). Published by S. Karger AG, Basel & (c)
\end{tabular} \\ Ling et al.: NEAT1 Promotes Deterioration of Hepatocellular Carcinoma}

functional annotations and KEGG pathways are presented in Fig. 9. The result of the KEGG pathway analysis revealed that the co-expressed genes are involved in several cancer-related pathways, such as "viral carcinogenesis", "transcriptional mis-regulation in cancer" and "P53 signaling pathway".

\section{Construction of the PPI network}

In total, 21 genes related to "viral carcinogenesis", "transcriptional mis-regulation in cancer" and "P53 signaling pathway" were selected to construct a PPI network (Fig. 10). A confidence score greater than 0.4 was set as the threshold for assessing associations between these genes. We found interactions among the following 14 genes: MDM2 (mouse double minute 2), SP1 (transcription factor specificity protein 1), MDM4 (mouse double minute 4), ATM (ATM serine/threonine kinase), CREBBP (cyclic AMP responsive element-binding protein), PMAIP1 (phorbol-12myristate-13-acetate-induced protein 1), TRAF5 (TNF receptor associated factor 5), SERPINB5 (serpin family $B$ member 5), CASP8 (caspase 8), TRAF1 (TNF receptor associated factor 1 ), KAT2A (lysine acetyltransferase 2A), HIST4H4 (histone cluster 4 H4 ), HIST1H2BF (histone cluster $1 \mathrm{H} 2 \mathrm{~B}$ family member f) and HIST1H4E (histone cluster 1 H4 family member e). Then, we evaluated the expression levels of the 14 genes involved in HCC and further investigated how their expression was correlated with that of NEAT1. Because the expression levels of the genes

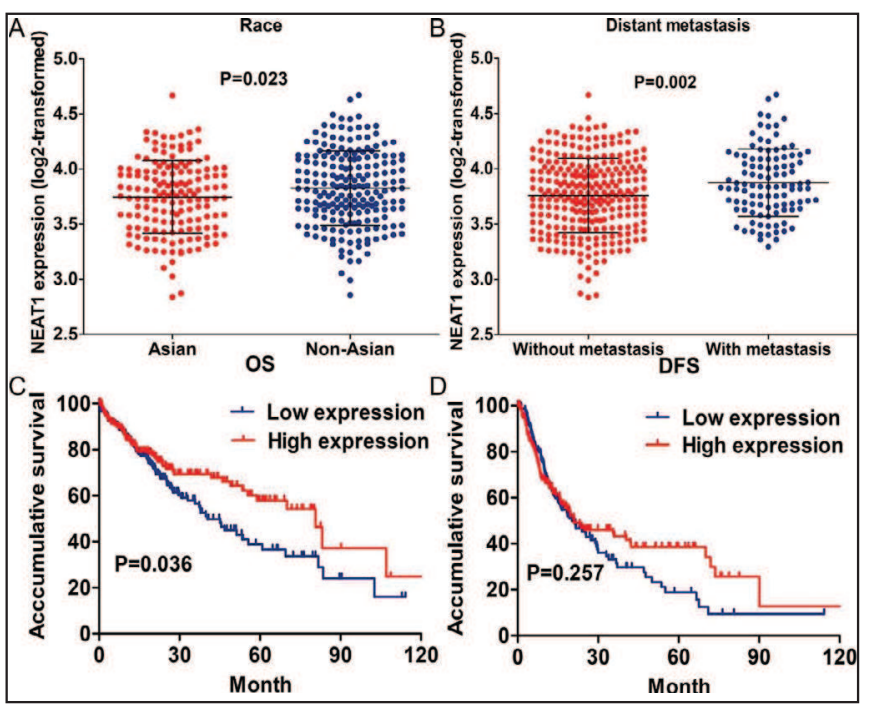

Fig. 7. Clinical value of NEAT1 in hepatocellular carcinoma (HCC). (A) Relationship between NEAT1 expression and race. (B) Relationship between NEAT1 expression and distant metastasis. (C) Relationship between NEAT1 expression and overall survival. (D) Relationship between NEAT1 expression and disease-free survival.

Table 2. Relationships between NEAT1 expression and clinical parameters. SD, standard deviation

\begin{tabular}{lccccc}
\hline Variables & Group & Sample size & $\begin{array}{c}\text { NEAT1 expression } \\
\text { (mean } \pm \text { SD })\end{array}$ & \multicolumn{2}{c}{$\begin{array}{c}\text { t-test } \\
\text { P-value }\end{array}$} \\
\hline Race & Non-Asian & 201 & $12.71 \pm 1.12$ & 2.254 & 0.025 \\
& Asian & 157 & $12.45 \pm 1.10$ & & \\
Gender & Male & 249 & $12.54 \pm 1.08$ & 1.320 & 0.188 \\
& Female & 121 & $12.70 \pm 1.15$ & & \\
Age & $\geq 65$ & 149 & $12.58 \pm 1.16$ & 0.122 & 0.903 \\
& $<65$ & 221 & $12.60 \pm 1.07$ & & \\
TNM stage & I-II & 256 & $12.67 \pm 1.10$ & 2.030 & 0.121 \\
\multirow{2}{*}{ Histologic grade } & III-IV & 90 & $12.39 \pm 1.14$ & & \\
& G1-G2 & 232 & $12.56 \pm 1.09$ & 0.735 & 0.463 \\
Lymph node metastasis & G3-G4 & 133 & $12.66 \pm 1.13$ & & \\
& No & 252 & $12.52 \pm 1.11$ & 1.943 & 0.053 \\
Distant metastasis & Yes & 117 & $12.76 \pm 1.07$ & & \\
\multirow{2}{*}{ Vascular invasion } & No & 266 & $12.48 \pm 1.12$ & 3.069 & 0.002 \\
& Yes & 100 & $12.87 \pm 1.07$ & & \\
& No & 206 & $12.58 \pm 1.11$ & 0.762 & 0.447 \\
\hline
\end{tabular}



Cellular Physiology Cell Physiol Biochem 2018;48:540-555

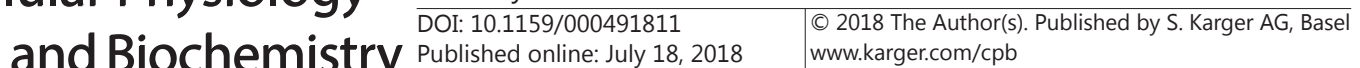

Table 3. Results of univariate and multivariate Cox regression analyses. OS, overall survival; HR, hazard ratio; CI, confidence interval

\begin{tabular}{|c|c|c|c|c|}
\hline \multirow[t]{2}{*}{ Variables } & \multicolumn{2}{|c|}{ Univariate analysis } & \multicolumn{2}{|c|}{ Multivariate analysis } \\
\hline & $\operatorname{HR}(95 \% \mathrm{CI})$ & $\mathrm{P}$-value & $\operatorname{HR}(95 \% \mathrm{CI})$ & $\mathrm{P}$-value \\
\hline Age & $1.237(0.875-1.748)$ & 0.228 & & \\
\hline Race & $1.311(0.905-1.899)$ & 0.152 & & \\
\hline Gender & $1.226(0.86-1.747)$ & 0.260 & & \\
\hline TNM stage & $2.448(1.689-3.548)$ & $<0.0001$ & $1.567(0.206-11.946)$ & 0.665 \\
\hline Histological grade & $1.12(0.781-1.606)$ & 0.539 & & \\
\hline Lymph node metastasis & $1.512(1.049-2.179)$ & 0.027 & $1.177(0.709-1.955)$ & 0.528 \\
\hline Distant metastasis & $1.678(1.164-2.419)$ & 0.005 & $1.648(0.995-2.728)$ & 0.052 \\
\hline Vascular invasion & $1.348(0.89-2.042)$ & 0.159 & & \\
\hline NEAT1 & $0.57(0.344-0.944)$ & 0.029 & $0.568(0.329-0.98)$ & 0.042 \\
\hline
\end{tabular}

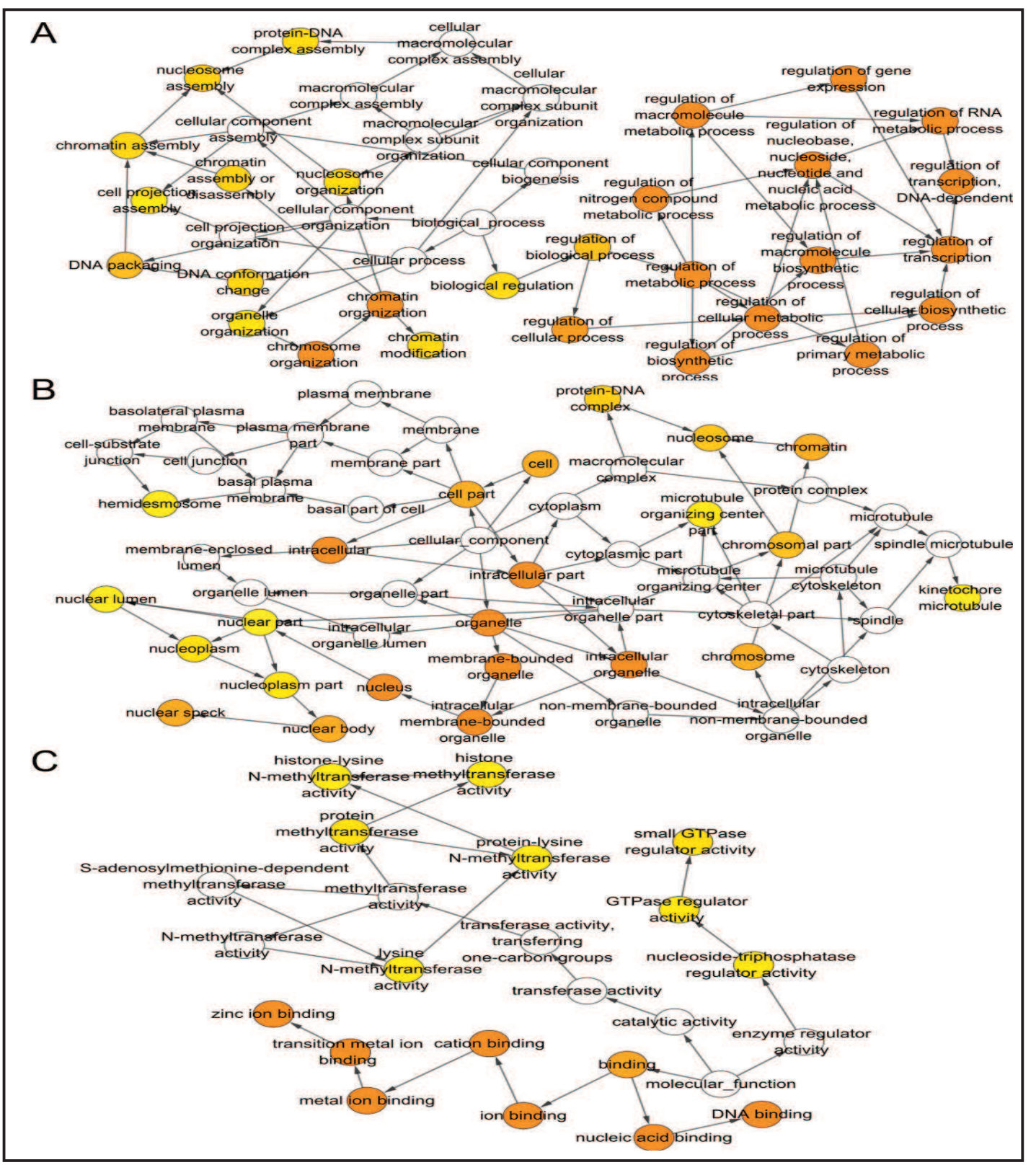

Fig. 8. Networks based on the Gene Ontology (GO) terms as constructed by the BINGO plugin for Cytoscape 3.3.0 software. (A) Biological process. (B) Cellular component. (C) Molecular function. 


\section{Cellular Physiology Cell Physiol Biochem 2018;48:540-555 \begin{tabular}{l|l} 
DOI: 10.1159/000491811 & O 2018 The Author(s). Published by S. Karger AG, Basel \\
www.karger.com/cpb
\end{tabular}

Fig. 9. The top five Gene Ontology (GO) items and Kyoto Encyclopedia of Genes and Genomes (KEGG) pathways of the genes coexpressed with NEAT1.

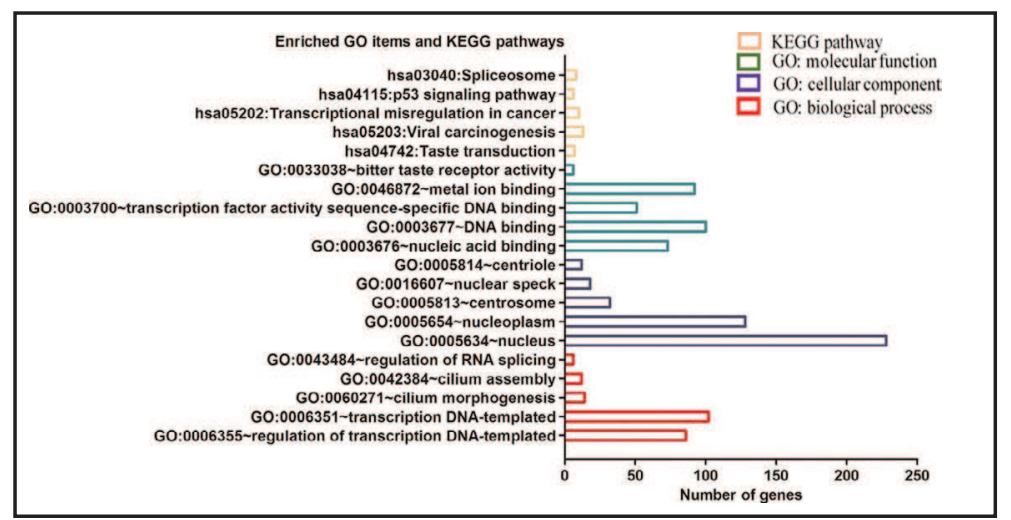

Fig. 10. Protein-protein interaction network of 21 genes that participate in cancer-related pathways.

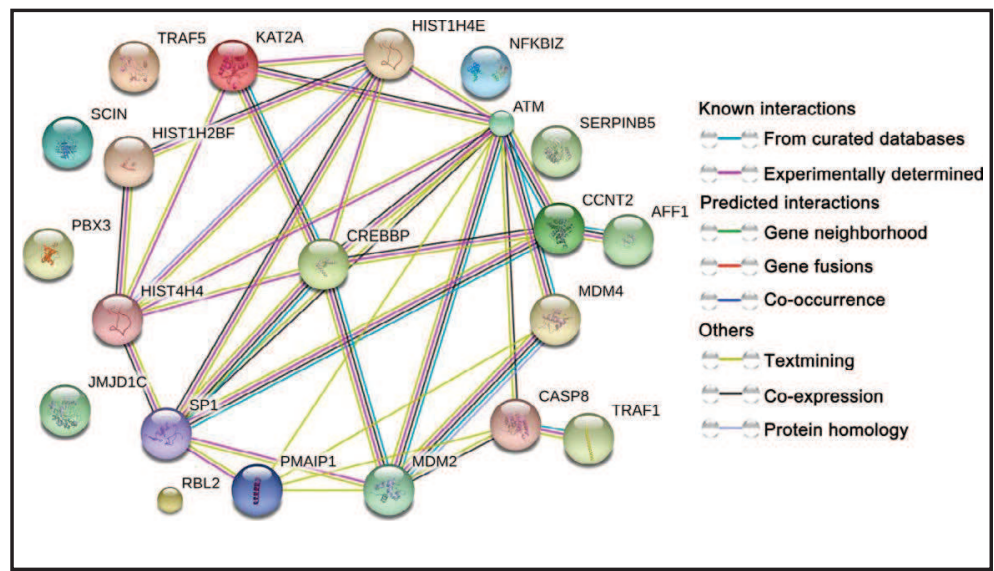

Fig. 11. Heatmap of the eight genes coexpressed with NEAT1 in hepatocellular carcinoma (HCC) based on data from The Cancer Genome Atlas. The heatmap was generated using the pheatmap package in $\mathrm{R}$.

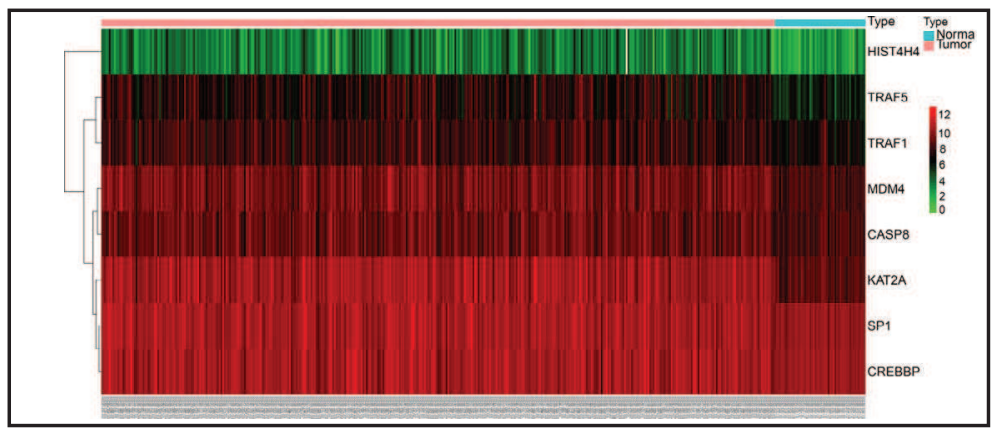

Fig. 12. Expression of the eight genes coexpressed with NEAT1 in hepatocellular carcinoma (HCC) based on data from The Cancer Genome Atlas: (A) SP1, (B) MDM4, (C) CREBBP, (D) TRAF5, (E) CASP8, (F) TRAF1, (G) KAT2A, (H) HIST4H4.

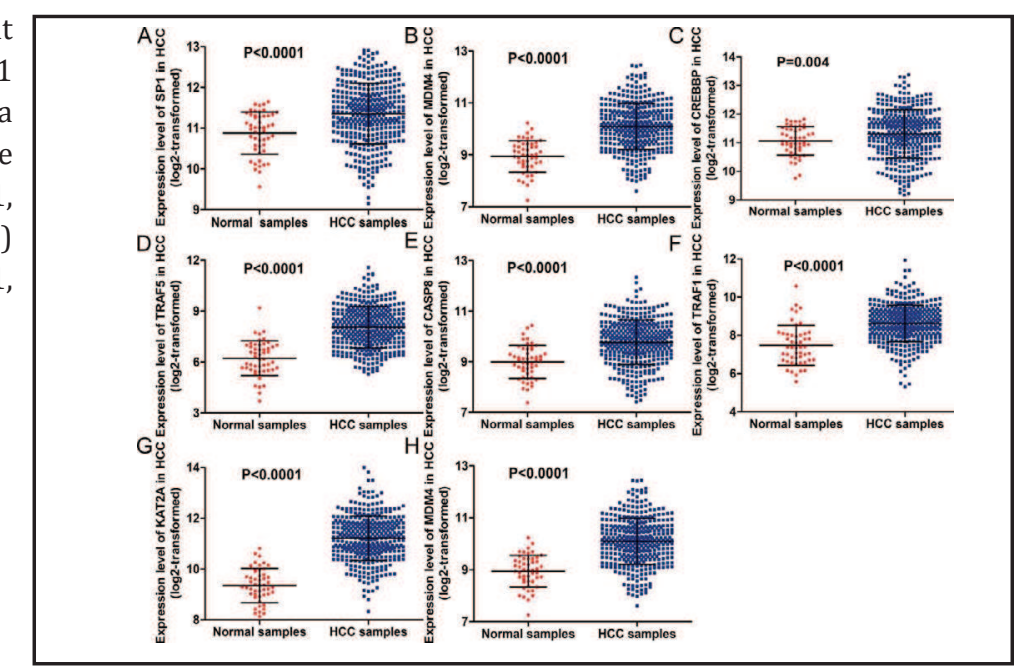




\section{Cellular Physiology Cell Physiol Biochem 2018;48:540-555

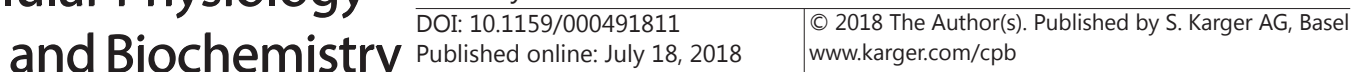

Ling et al.: NEAT1 Promotes Deterioration of Hepatocellular Carcinoma

HIST1H4E were zero in more than $10 \%$ of the samples, we removed them from the expression and correlation analyses. Our results indicated that the eight genes SP1, MDM4, CREBBP, TRAF5, CASP8, TRAF1, KAT2A, and HIST4H4 were not only significantly upregulated in HCC (Table 4, Figs. 11 and 12) but also remarkably associated with NEAT1 (Table 4, Fig. 13). Additionally, the expression patterns of the proteins encoded by these eight genes were validated based on the Human Protein Atlas database (http://www. proteinatlas.org/), and the results are displayed in Fig. 14. Our results indicate that NEAT1 may exert its unique role in HCC through interactions with these eight genes.

\section{Discussion}

With the innovation of genomic and molecular technologies, the functions of IncRNAs in various cancers have received increasing attention in recent years. Accordingly, lncRNAs have been revealed to perform complicated roles in carcinogenesis and cancer progression at the chromatin organizational, translational, and post-translational levels [34].

Fig. 14. Immunohistochemistry staining of the proteins encoded by the eight genes coexpressed with NEAT1: (A) low nuclear SP1 expression in normal liver tissue, (B) moderate nuclear SP1 expression in hepatocellular carcinoma (HCC) tissue, (C) low nuclear MDM4 expression in normal liver tissue, (D) high nuclear MDM4 expression in HCC tissue, (E) low nuclear CREBBP expression in normal liver tissue, (F) moderate nuclear CREBBP expression in HCC tissue, (G) moderate cytoplasmic/membranous TRAF5 expression in normal liver tissue, (H) high cytoplasmic/ membranous TRAF5 expression in HCC tissue, (I) low cytoplasmic/membranous CASP8 expression in normal liver tissue, (J) high cytoplasmic/ membranous CASP8 expression in HCC tissue, (K) low cytoplasmic/membranous TRAF1 expression in normal liver tissue, (L) high cytoplasmic/ membranous TRAF1 expression in HCC tissue, (M) low cytoplasmic/membranous KAT2A expression in normal liver tissue, (N) high moderate cytoplasmic/membranous KAT2A expression in HCC tissue, (O) low nuclear HIST4H4 expression in normal liver tissue, (P) high nuclear HIST4H4 protein expression in HCC tissue. and their correlations with NEAT1. HCC, hepatocellular carcinoma; SD, standard deviation

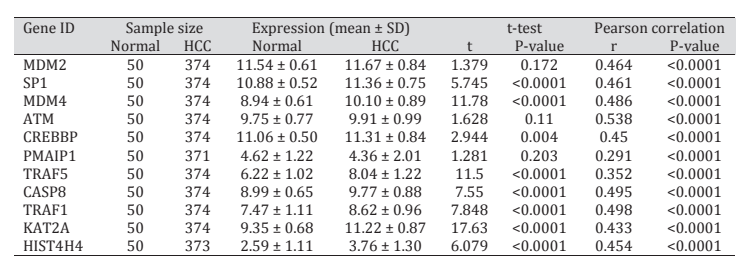

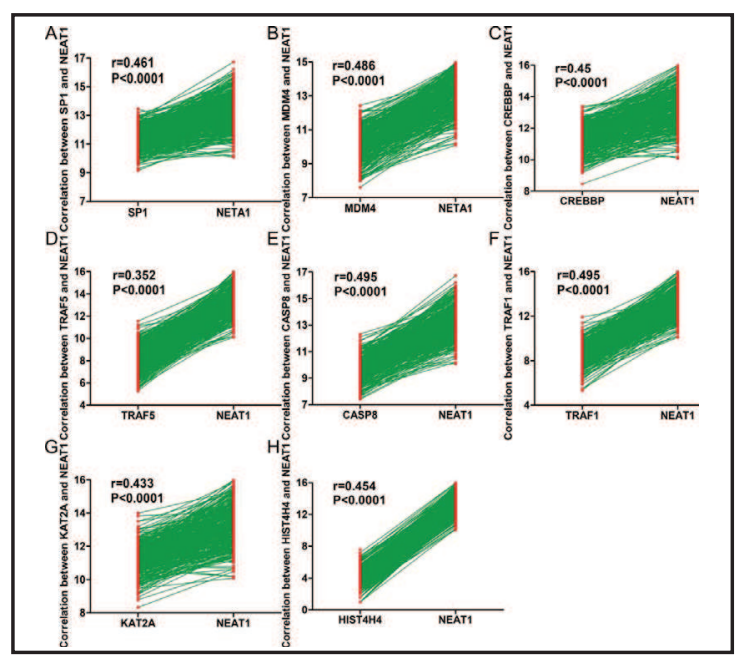

Fig. 13. Correlations in expression between the eight genes and NEAT1 in hepatocellular carcinoma based on data from The Cancer Genome Atlas: (A) SP1, (B) MDM4, (C) CREBBP, (D) TRAF5, (E) CASP8, (F) TRAF1, (G) KAT2A, (H) HIST4H4.

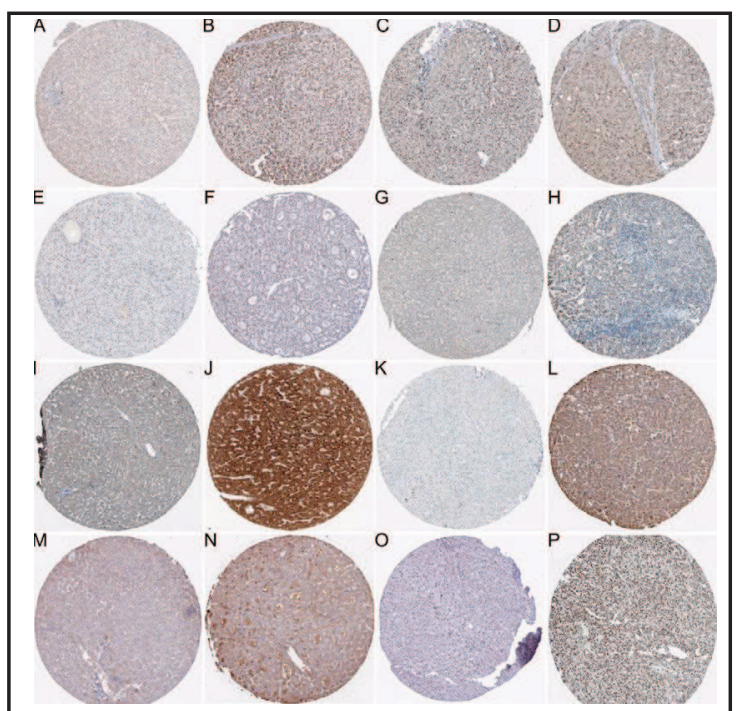

Table 4. Expression of 11 cancer-related genes in HCC 


\section{Cellular Physiology Cell Physiol Biochem 2018;48:540-555 \begin{tabular}{l|l|l|l|l|l} 
DOI: 10.1159/000491811 & () 2018 The Author(s). Published by S. Karger AG, Basel
\end{tabular}

Ling et al.: NEAT1 Promotes Deterioration of Hepatocellular Carcinoma

NEAT1, a lncRNA that participates in the formation of the paraspeckle, has also been demonstrated to be involved in the occurrence and development of many malignancies. Peng et al. [35] detected the expression of NEAT1 in 56 colorectal cancer (CRC) and adjacent noncancerous tissues and found that NEAT1 was upregulated in CRC tissues. The authors found that knockdown of NEAT1 in CRC cells could significantly inhibit cell growth and facilitate cell apoptosis, indicating that NEAT1 may act as an oncogene in CRC. However, Idogawa et al. [36] silenced NEAT1 by transferring NEAT1 siRNA into osteosarcoma U2OS cells and lung cancer A549 cells and discovered that NEAT1 knockdown could promote cell growth, which suggested that NEAT1 may be a tumor suppressor. The effect of NEAT1 on HCC has been explored in previous studies. Fujimoto et al. [37] pursued a characterization of noncoding mutations in liver cancer and found that NEAT1 contained a significantly high number of mutations in liver cancer, which may cause aberrant expression of NEAT1 in liver cancer. Then, the authors silenced NEAT1 expression in HepG2 cells and found that the inhibition of NEAT1 expression significantly decreased HCC cell invasion but did not affect cell proliferation. A study conducted by Mang et al. [22] showed that knockdown of NEAT1 inhibited the proliferation and invasion of HCC HepG2 and SMMC-7721 cells. A study performed by Wang et al. [23] also demonstrated that silencing NEAT1 in vitro could obviously arrest HCC cell proliferation and invasion. However, the effect of NEATI on HCC cell apoptosis has not been explored to date. In the present study, we detected the effects of NEAT1 on proliferation, apoptosis, migration, and invasion of HCC cells by transfecting NEAT1 siRNA into HepB3 and/or HepG2 cells. Our results indicate NEAT1 siRNA observably inhibits proliferation, migration, and invasion of HCC cells, which was consistent with previous studies [22, 23, 38]. More importantly, we also found that NEAT1 siRNA could significantly induce HCC cells to undergo apoptosis. These findings indicate that NEAT1 may promote tumor deterioration in HCC.

To further probe the exact role of NEAT1 in HCC, we obtained relevant RNA-seq and microarray datasets. Our research group has previously performed a comprehensive analysis of the expression levels of NEAT1 in digestive system malignancies based on data from TCGA, GEO, ArrayExpress, and Oncomine [21]. The combined result based on 13 RNA-seq and microarray datasets showed that NEAT1 was downregulated in HCC. However, the result should be interpreted cautiously because a remarkable heterogeneity exists, which may greatly reduce the accuracy and reliability of the result. To avoid the influence of inter-study heterogeneity on our result, we only included RNA-seq and microarray datasets from TCGA and Oncomine. Additionally, we performed RT-qPCR to validate the expression of NEAT1. Then, a combined strategy using RNA-seq, gene chip, and RT-qPCR data was employed to systematically investigate the expression levels of NEAT1 in HCC. We found that NEAT1 was significantly up-regulated in HCC, which was consistent with previous studies [22, 23, 38]. Compared with those previous studies, our present study included more cases.

A study conducted by Li et al. [39] showed that overexpression of NEAT1 could drive endometrial adenocarcinoma (EAC) cells in the Sphase and thus boost tumor cell proliferation. Additionally, the overexpression of NEAT1 in EAC cells could upregulate metastasis-related genes, such as matrix metallopeptidase 7 (MMP-7), MMP-2, insulin-like growth factor 1 , and c-myc. In the present study, we also found that high NEAT1 expression was related to metastasis of HCC. We hypothesize that NEAT1 facilitates HCC metastasis by regulating some metastasis-related genes. Further studies are needed to validate our conjecture.

The prognostic value of NEAT1 in HCC was also assessed in this study. The results indicated that high NEAT1 expression was closely associated with better overall survival and could serve as an independent prognostic factor for predicting the prognosis of patients with HCC. A study conducted by Idogawa et al. [36] based on microarray datasets from GEO also showed that the survival rate was higher among cancer patients with high NEAT1 expression relative to patients with low NEAT1 expression. The authors analyzed chromatin immunoprecipitation-sequencing data and found that NEAT1 was a transcriptional target of tumor suppressor P53 and that overexpressed NEAT1 could enhance the tumor suppressor effect of P53. Therefore, patients with high expression of NEAT1 have a favorable survival 


\section{Cellular Physiology Cell Physiol Biochem 2018;48:540-555 and Biochemistry

Ling et al.: NEAT1 Promotes Deterioration of Hepatocellular Carcinoma

outcome in several malignancies. In addition, a study performed by Gao et al. [40] showed that enhancing the expression level of NEAT1 in leukemia cells could significantly increase the sensitivity of tumor cells to chemotherapy. Therefore, we speculate that patients with high expression levels of NEAT1 in their HCCs will have better chemotherapeutic responses and prognoses. Further large-scale clinical studies are needed to validate our hypothesis.

To preliminarily explore the molecular mechanism of NEAT1 in HCC, we performed GO and KEGG pathway analyses on 1, 250 genes coexpressed with NEAT1 from cBioPortal, a public database that collects and processes data from TCGA. We found that these co-expressed genes were involved in some cancer-related pathways, such as "regulation of transcription", "transcriptional mis-regulation in cancer" and "P53 signaling pathway". Then we selected 21 genes that participated in the above three pathways to construct a PPI network. Among the 21 co-expressed genes, 14 genes were shown to interact with each other. The expression levels of the 14 genes and the correlations between them and NEAT1 were further evaluated. We found that the genes SP1, MDM4, CREBBP, TRAF5, CASP8, TRAF1, KAT2A, and HIST4H4 were not only upregulated in HCC but also closely linked with NEAT1, indicating that NEAT1 may promote HCC carcinogenesis by interacting with these eight genes.

Accumulated data have demonstrated that the overexpression of CREBBP, SP1, and MDM4 play central roles in various malignant tumors including HCC. Servillo et al. [41] found that CREBBP increased hepatocyte proliferation. Abramovitch et al. [42] demonstrated that CREBBP could promote HCC progression by stimulating tumor cell growth and reducing cell apoptosis in vitro and in vivo. Huang et al. [43] demonstrated that SP1 significantly upregulated lncRNA MALAT1 in HCC and further activated tumor progression. Gandhy et al. [44] proposed that SP1 promoted tumor cell proliferation and migration by increasing the expression of IncRNA HULC in HCC. MADM4, a P53 binding protein homolog, is a critical negative modulator of tumor suppressor P53 [45]. Pellegrino et al. [46] showed that MDM4 acted as an oncogene in HCC by interacting with the PI3K-AKT/mTOR pathways. The authors also demonstrated that reducing the expression level of MDM4 by inhibiting the PI3K/AKT/ mTOR pathways could reactivate tumor inhibition by P53 and subsequently inhibit the progression of HCC.

Both KAT2A and HIST4H4 play central roles in transcriptional regulation and have been demonstrated to exert roles in gastric carcinoma $[47,48]$. However, their biological functions in HCC have not yet been studied. Accordingly, further in vitro and in vivo experiments are necessary to uncover the exact roles of KAT2A and HIST4H4 in HCC.

TRAF1, TRAF5, and CASP8 are apoptosis-related genes [49]. TRAF1 and TRAF5 are members of the TRAF family that have been shown to participate in cell apoptosis by regulating the NF- $\mathrm{KB}$ (nuclear factor kappa B) and ASK1/JNK signaling pathways [50-52]. Previous studies have shown that TRAF1 and TRAF5 are related to various malignancies including HCC $[53,54]$. CASP8, an extremely critical molecule in the caspase-dependent apoptotic signaling pathway, is an important member of the cysteinyl aspartate-specific proteinase (caspase) family. The caspase family contains many well-known apoptosis-related proteinases, such as CASP2, CASP3, CASP6, CASP7, CASP8, CASP9, CASP10, and CASP11, which play key roles in cell apoptosis. A large number of studies have provided evidence that these caspases are involved in the occurrence and progression of HCC [55-59]. However, the relationships between these caspases and NEAT1 have not yet been investigated. In the current study, we verified that NEAT1 siRNA could induce HCC cells to undergo apoptosis in vitro. We hypothesize that NEAT1 inhibits apoptosis of HCC cells by interacting with these apoptosis-related genes. Further and stricter in vitro and in vivo investigations are needed to confirm our findings.

Our comprehensive analyses of in vitro experiments as well as RNA-seq and microarray datasets and in-house RT-qPCR suggest that NEAT1 could promote the deterioration of HCC. More importantly, NEAT1 could serve as a diagnostic and prognostic biomarker that provides a new perspective for molecular-targeted treatment of HCC in clinical settings. 


\section{Cellular Physiology \\ Cell Physiol Biochem 2018;48:540-555 and Biochemistry

Ling et al.: NEAT1 Promotes Deterioration of Hepatocellular Carcinoma

\section{Acknowledgements}

This study was supported by the Natural Science Foundation of Guangxi, China (2017GXNSFAA198017), the National Natural Science Foundation of China (NSFC81560489), the Medical Excellence Award Funded by the Creative Research Development Grant from the First Affiliated Hospital of Guangxi Medical University, a grant from the Open Foundation of Guangxi Medicine Science Laboratory, China (KFJJ2011-27), the project for improving the basic ability of young teachers in colleges and universities in Guangxi (YB2014070), the Guangxi Medical University Training Program for Distinguished Young Scholars (2017), and the Guangxi Medical University Student Innovation Plan (201610598099).

\section{Disclosure Statement}

The authors declare that they have no competing interests.

\section{References}

$>1$ Siegel RL, Miller KD, Jemal A: Cancer Statistics, 2017. CA Cancer J Clin 2017;67:7-30.

-2 Hsieh WY, Chen PH, Lin IY, Su CW, Chao Y, Huo TI, Huang YH, Hou MC, Lin HC, Wu JC: The impact of esophagogastric varices on the prognosis of patients with hepatocellular carcinoma. Sci Rep 2017;7:42577.

3 Flynn RA, Chang HY: Long noncoding RNAs in cell-fate programming and reprogramming. Cell Stem Cell 2014;14:752-761.

4 Rinn JL, Chang HY: Genome regulation by long noncoding RNAs. Annu Rev Biochem 2012;81:145-166.

5 Li T, Mo X, Fu L, Xiao B, Guo J: Molecular mechanisms of long noncoding RNAs on gastric cancer. Oncotarget 2016; 7:8601-8612.

6 Huarte M, Rinn JL: Large non-coding RNAs: missing links in cancer? Hum Mol Genet 2010;19:R152-161.

7 Lee JT: Epigenetic regulation by long noncoding RNAs. Science 2012;338:1435-1439.

8 Batista PJ, Chang HY: Long noncoding RNAs: cellular address codes in development and disease. Cell 2013;152:1298-1307.

-9 Panzitt K, Tschernatsch MM, Guelly C, Moustafa T, Stradner M, Strohmaier HM, Buck CR, Denk H, Schroeder R, Trauner M, Zatloukal K: Characterization of HULC, a novel gene with striking up-regulation in hepatocellular carcinoma, as noncoding RNA. Gastroenterology 2007;132:330-342.

-10 Sui J, Yang X, Qi W, Guo K, Gao Z, Wang L, Sun D: Long Non-Coding RNA Linc-USP16 Functions As a Tumour Suppressor in Hepatocellular Carcinoma by Regulating PTEN Expression. Cell Physiol Biochem 2017;44:1188-1198.

11 Wang F, Ying HQ, He BS, Pan YQ, Deng QW, Sun HL, Chen J, Liu X, Wang SK: Upregulated lncRNA-UCA1 contributes to progression of hepatocellular carcinoma through inhibition of miR-216b and activation of FGFR1/ERK signaling pathway. Oncotarget 2015;6:7899-7917.

12 Sunwoo H, Dinger ME, Wilusz JE, Amaral PP, Mattick JS, Spector DL: MEN epsilon/beta nuclear-retained non-coding RNAs are up-regulated upon muscle differentiation and are essential components of paraspeckles. Genome Res 2009;19:347-359.

13 Naganuma T, Hirose T: Paraspeckle formation during the biogenesis of long non-coding RNAs. RNA Biol 2013;10:456-461.

14 Qian K, Liu G, Tang Z, Hu Y, Fang Y, Chen Z, Xu X: The long non-coding RNA NEAT1 interacted with miR-101 modulates breast cancer growth by targeting EZH2. Arch Biochem Biophys 2017;615:1-9.

15 Sun C, Li S, Zhang F, Xi Y, Wang L, Bi Y, Li D: Long non-coding RNA NEAT1 promotes non-small cell lung cancer progression through regulation of miR-377-3p-E2F3 pathway. Oncotarget 2016;7:51784-51814.

-16 Wang P, Wu T, Zhou H, Jin Q He G, Yu H, Xuan L, Wang X, Tian L, Sun Y, Liu M, Qu L: Long noncoding RNA NEAT1 promotes laryngeal squamous cell cancer through regulating miR-107/CDK6 pathway. J Exp Clin Cancer Res 2016;35:22.

17 Fu JW, Kong Y, Sun X: Long noncoding RNA NEAT1 is an unfavorable prognostic factor and regulates migration and invasion in gastric cancer. J Cancer Res Clin Oncol 2016;142:1571-1579.

18 Lu Y, Li T, Wei G, Liu L, Chen Q Xu L, Zhang K, Zeng D, Liao R: The long non-coding RNA NEAT1 regulates epithelial to mesenchymal transition and radioresistance in through miR-204/ZEB1 axis in nasopharyngeal carcinoma. Tumour Biol 2016;37:11733-11741. 


\section{Cellular Physiology Cell Physiol Biochem 2018;48:540-555 \begin{tabular}{c|l|l} 
DOI: 10.1159/000491811 & (c) 2018 The Author(s). Published by S. Karger AG, Basel
\end{tabular} and Biochemistry Published online: July 18, 2018 www.karger.com/cpb}

Ling et al.: NEAT1 Promotes Deterioration of Hepatocellular Carcinoma

19 Huang B, Liu C, Wu Q, Zhang J, Min Q, Sheng T, Wang X, Zou Y: Long non-coding RNA NEAT1 facilitates pancreatic cancer progression through negative modulation of miR-506-3p. Biochem Biophys Res Commun 2017;482:828-834.

20 Wu Y, Yang L, Zhao J, Li C, Nie J, Liu F, Zhuo C, Zheng Y, Li B, Wang Z, Xu Y: Nuclear-enriched abundant transcript 1 as a diagnostic and prognostic biomarker in colorectal cancer. Mol Cancer 2015;14:191.

21 Xiong DD, Feng ZB, Cen WL, Zeng JJ, Liang L, Tang RX, Gan XN, Liang HW, Li ZY, Chen G, Luo DZ: The clinical value of IncRNA NEAT1 in digestive system malignancies: A comprehensive investigation based on 57 microarray and RNA-seq datasets. Oncotarget 2017;8:17665-17683.

22 Mang Y, Li L, Ran J, Zhang S, Liu J, Li L, Chen Y, Liu J, Gao Y, Ren G: Long noncoding RNA NEAT1 promotes cell proliferation and invasion by regulating hnRNP A2 expression in hepatocellular carcinoma cells. Onco Targets Ther 2017;10:1003-1016.

-23 Wang Z, Zou Q Song M, Chen J: NEAT1 promotes cell proliferation and invasion in hepatocellular carcinoma by negative regulating miR-613 expression. Biomed Pharmacother 2017;94:612-618.

24 Rong M, Chen G, Dang Y: Increased miR-221 expression in hepatocellular carcinoma tissues and its role in enhancing cell growth and inhibiting apoptosis in vitro. BMC Cancer 2013;13:21.

25 Chen G, Umelo IA, Lv S, Teugels E, Fostier K, Kronenberger P, Dewaele A, Sadones J, Geers C, De Greve J: miR-146a inhibits cell growth, cell migration and induces apoptosis in non-small cell lung cancer cells. PLoS One 2013;8:e60317.

26 Chen G, Kronenberger P, Teugels E, De Greve J: Influence of RT-qPCR primer position on EGFR interference efficacy in lung cancer cells. Biol Proced Online 2010;13:1.

27 Chen G, Kronenberger P, Teugels E, Umelo IA, De Greve J: Effect of siRNAs targeting the EGFR T790M mutation in a non-small cell lung cancer cell line resistant to EGFR tyrosine kinase inhibitors and combination with various agents. Biochem Biophys Res Commun 2013;431:623-629.

28 Deng M, Bragelmann J, Schultze JL, Perner S: Web-TCGA: an online platform for integrated analysis of molecular cancer data sets. BMC Bioinformatics 2016;17:72.

-29 Rhodes DR, Yu J, Shanker K, Deshpande N, Varambally R, Ghosh D, Barrette T, Pandey A, Chinnaiyan AM: ONCOMINE: a cancer microarray database and integrated data-mining platform. Neoplasia 2004;6:1-6.

-30 Harbord RM, Egger M, Sterne JA: A modified test for small-study effects in meta-analyses of controlled trials with binary endpoints. Stat Med 2006;25:3443-3457.

-31 Gao J, Aksoy BA, Dogrusoz U, Dresdner G, Gross B, Sumer SO, Sun Y, Jacobsen A, Sinha R, Larsson E, Cerami E, Sander C, Schultz N: Integrative analysis of complex cancer genomics and clinical profiles using the cBioPortal. Sci Signal 2013;6:pl1.

-32 Jiao X, Sherman BT, Huang da W, Stephens R, Baseler MW, Lane HC, Lempicki RA: DAVID-WS: a stateful web service to facilitate gene/protein list analysis. Bioinformatics 2012;28:1805-1806.

-33 Szklarczyk D, Morris JH, Cook H, Kuhn M, Wyder S, Simonovic M, Santos A, Doncheva NT, Roth A, Bork P, Jensen LJ, von Mering C: The STRING database in 2017: quality-controlled protein-protein association networks, made broadly accessible. Nucleic Acids Res 2017;45:D362-D368.

-34 Yang G, Lu X, Yuan L: LncRNA: a link between RNA and cancer. Biochim Biophys Acta 2014;1839:10971109.

-35 Peng W, Wang Z, Fan H: LncRNA NEAT1 Impacts Cell Proliferation and Apoptosis of Colorectal Cancer via Regulation of Akt Signaling. Pathol Oncol Res 2016;23:651-656.

-36 Idogawa M, Ohashi T, Sasaki Y, Nakase H, Tokino T: Long non-coding RNA NEAT1 is a transcriptional target of p53 and modulates p53-induced transactivation and tumor-suppressor function. Int J Cancer 2017;140:2785-2791.

-37 Fujimoto A, Furuta M, Totoki Y, Tsunoda T, Kato M, Shiraishi Y, Tanaka H, Taniguchi H, Kawakami Y, Ueno M, Gotoh K, Ariizumi S, Wardell CP, Hayami S, Nakamura T, Aikata H, Arihiro K, Boroevich KA: Whole-genome mutational landscape and characterization of noncoding and structural mutations in liver cancer. Nat Genet 2016;48:500-509.

-38 Liu Z, Chang Q, Yang F, Liu B, Yao HW, Bai ZG, Pu CS, Ma XM, Yang Y, Wang TT, Guo W, Zhou XN, Zhang ZT: Long non-coding RNA NEAT1 overexpression is associated with unfavorable prognosis in patients with hepatocellular carcinoma after hepatectomy: A Chinese population-based study. Eur J Surg Oncol 2017;43:1697-1703.

-39 Li Z, Wei D, Yang C, Sun H, Lu T, Kuang D: Overexpression of long noncoding RNA, NEAT1 promotes cell proliferation, invasion and migration in endometrial endometrioid adenocarcinoma. Biomed Pharmacother 2016;84:244-251. 


\section{Cellular Physiology \\ Cell Physiol Biochem 2018;48:540-555 and Biochemistry

Ling et al.: NEAT1 Promotes Deterioration of Hepatocellular Carcinoma

40 Gao C, Zhang J, Wang Q, Ren C: Overexpression of IncRNA NEAT1 mitigates multidrug resistance by inhibiting ABCG2 in leukemia. Oncol Lett 2016;12:1051-1057.

41 Servillo G, Della Fazia MA, Sassone-Corsi P: Coupling cAMP signaling to transcription in the liver: pivotal role of CREB and CREM. Exp Cell Res 2002;275:143-154.

42 Abramovitch R, Tavor E, Jacob-Hirsch J, Zeira E, Amariglio N, Pappo O, Rechavi G, Galun E, Honigman A: A pivotal role of cyclic AMP-responsive element binding protein in tumor progression. Cancer Res 2004;64:1338-1346.

43 Huang Z, Huang L, Shen S, Li J, Lu H, Mo W, Dang Y, Luo D, Chen G, Feng Z: Sp1 cooperates with Sp3 to upregulate MALAT1 expression in human hepatocellular carcinoma. Oncol Rep 2015;34:2403-2412.

\$4 Gandhy SU, Imanirad P, Jin UH, Nair V, Hedrick E, Cheng Y, Corton JC, Kim K, Safe S: Specificity protein (Sp) transcription factors and metformin regulate expression of the long non-coding RNA HULC. Oncotarget 2015;6:26359-26372.

45 Bardot B, Toledo F: Targeting MDM4 Splicing in Cancers. Genes (Basel) 2017;8. DOI: 10.3390/ genes8020082.

46 Pellegrino R, Calvisi DF, Neumann O, Kolluru V, Wesely J, Chen X, Wang C, Wuestefeld T, Ladu S, Elgohary N, Bermejo JL, Radlwimmer B, Zornig M, Zender L, Dombrowski F, Evert M, Schirmacher P, Longerich T: EEF1A2 inactivates p53 by way of PI3K/AKT/mTOR-dependent stabilization of MDM4 in hepatocellular carcinoma. Hepatology 2014;59:1886-1899.

-47 Sun TT, He J, Liang Q Ren LL, Yan TT, Yu TC, Tang JY, Bao YJ, Hu Y, Lin Y, Sun D, Chen YX, Hong J, Chen H, Zou W, Fang JY: LncRNA GClnc1 Promotes Gastric Carcinogenesis and May Act as a Modular Scaffold of WDR5 and KAT2A Complexes to Specify the Histone Modification Pattern. Cancer Discov 2016;6:784-801.

-48 Seidl C, Port M, Apostolidis C, Bruchertseifer F, Schwaiger M, Senekowitsch-Schmidtke R, Abend M: Differential gene expression triggered by highly cytotoxic alpha-emitter-immunoconjugates in gastric cancer cells. Invest New Drugs 2010;28:49-60.

-49 Gu Q Wang JD, Xia HH, Lin MC, He H, Zou B, Tu SP, Yang Y, Liu XG, Lam SK, Wong WM, Chan AO, Yuen MF, Kung HF, Wong BC: Activation of the caspase-8/Bid and Bax pathways in aspirin-induced apoptosis in gastric cancer. Carcinogenesis 2005;26:541-546.

-50 Hoeflich KP, Yeh WC, Yao Z, Mak TW, Woodgett JR: Mediation of TNF receptor-associated factor effector functions by apoptosis signal-regulating kinase-1 (ASK1). Oncogene 1999;18:5814-5820.

-51 Compagno M, Lim WK, Grunn A, Nandula SV, Brahmachary M, Shen Q, Bertoni F, Ponzoni M, Scandurra M, Califano A, Bhagat G, Chadburn A, Dalla-Favera R, Pasqualucci L: Mutations of multiple genes cause deregulation of NF-kappaB in diffuse large B-cell lymphoma. Nature 2009;459:717-721.

-52 Shin DH, Park KW, Wu LC, Hong JW: ZAS3 promotes TNFalpha-induced apoptosis by blocking NFvarkappaB-activated expression of the anti-apoptotic genes TRAF1 and TRAF2. BMB Rep 2011;44:267272.

-53 Song R, Song H, Liang Y, Yin D, Zhang H, Zheng T, Wang J, Lu Z, Song X, Pei T, Qin Y, Li Y, Xie C, Sun B, Shi H, Li S, Meng X, Yang G, Pan S, Zhu J, Qi S, Jiang H, Zhang Z, Liu L: Reciprocal activation between ATPase inhibitory factor 1 and NF-kappaB drives hepatocellular carcinoma angiogenesis and metastasis. Hepatology 2014;60:1659-1673.

54 Chen Z, Zhao L, Zhao F, Yang G, Wang J: MicroRNA-26b regulates cancer proliferation migration and cell cycle transition by suppressing TRAF5 in esophageal squamous cell carcinoma. Am J Transl Res 2016;8:1957-1970.

55 Wang X, Zeng J, Wang L, Zhang X, Liu Z, Zhang H, Dong J: Overexpression of microRNA-133b is associated with the increased survival of patients with hepatocellular carcinoma after curative hepatectomy: Involvement of the EGFR/PI3K/Akt/mTOR signaling pathway. Oncol Rep 2017;38:141-150.

-56 Zhu LM, Shi DM, Dai Q, Cheng XJ, Yao WY, Sun PH, Ding Y, Qiao MM, Wu YL, Jiang SH, Tu SP: Tumor suppressor XAF1 induces apoptosis, inhibits angiogenesis and inhibits tumor growth in hepatocellular carcinoma. Oncotarget 2014;5:5403-5415.

-57 Qing T, Yamin Z, Guijie W, Yan J, Zhongyang S: STAT6 silencing induces hepatocellular carcinoma-derived cell apoptosis and growth inhibition by decreasing the RANKL expression. Biomed Pharmacother 2017;92:1-6.

58 Sharula, Wu Z: Regulation of Apoptosis by SYB in HepG2 Liver Cancer Cells is Mediated by the P53/Caspase 9 Axis. Anticancer Agents Med Chem 2017;17:941-947.

59 Koschny R, Brost S, Hinz U, Sykora J, Batke EM, Singer S, Breuhahn K, Stremmel W, Walczak H, Schemmer P, Schirmacher P, Ganten TM: Cytosolic and nuclear caspase-8 have opposite impact on survival after liver resection for hepatocellular carcinoma. BMC Cancer 2013;13:532. 